\title{
EVALUATING THE SPATIAL-SEASONAL VARIATION, HETEROGENEITY AND DISTRIBUTION OF URBAN THERMAL ENVIRONMENT: CASE STUDY OF NANJING, CHINA
}

\author{
Xiang Kang ${ }^{1}$, Jianjun $\operatorname{Pan}^{2, *}$ \\ ${ }^{1}$ College of Public Administration, Nanjing Agricultural University, Nanjing 210095, China - Kangxiang9523@163.com \\ ${ }^{2}$ College of Resources and Environmental Sciences, Nanjing Agricultural University, Nanjing 210095, China - jpan@njau.edu.cn
}

Commission III, WG III/8

KEY WORDS: Urban Thermal Environment, Urban Heat Island, Landsat 8, Spatial-seasonal Variation

\begin{abstract}
:
Urban thermal environment (UTE), as a important parameter in urban ecosystem, strongly and directly linking to urban development and human health. In recently decades, rapid urbanization and population development resulted in serious urban thermal environment problem particularly the urban heat island(UHI) phenomenon. Today, it's urgent to control and curb urban thermal environment based on the UTE's spatial-temporal characteristics, in addition, the seasonality of UTE lacked in-depth understanding, which is also a significant question in UTE management, a better understanding the UTE will help human improve governing efficiency and effect. Thus, in our study, we investigated the spatial-seasonal variation and distribution of UTE by statistic analysis, spatial index analysis and landscape metric analysis. We found that: there has a significant spatial and temporal differences on UTE under different seasons, the UHI intensity and mean LST showing a significant difference and stability, additionally, "heat island" of urban showing a cluster trend in urban space particularly in high UHI intensity seasons. These results extend our understanding on the spatial-seasonal variation, heterogeneity and distribution of UTE and which can provide very significant reference and information for urban decision-makers to govern UTE.
\end{abstract}

\section{INTRODUCTION}

In the 21st century, urbanization has already became a worldwide tendency with an unprecedented speed over the past decades. More than 55\% world's population living in the urban area, which will more than $68 \%$ in 2025 reported by the 2018 Revision of World Urbanization Prospects(Chakraborty and Lee, 2019; United Nations, 2018; Yu et al., 2019; Zhou et al., 2014). Urban area, as the crucial living space of human being, will occupy an more important position of word, particularly in the future. Increasing population not only promotes the socialeconomic development, but also causes negative effect on the urban system, such as the rapid urban expansion, air pollution, traffic jam, surface temperature increasing, biodiversity reduction, energy consumption and so on(Bhati and Mohan, 2015; Zhou et al., 2018). One of the most serious problems is the urban heat island(UHI) phenomenon, which influences the urban thermal environment seriously(Deilami et al., 2018). This phenomenon also caused by the urban development and population increasing, because the urban development meant the change of urban physical properties in land surface, much natural and semi-natural land surface transformed into impervious surface(Yu et al., 2019). These changes can induce the temperature of urban region were much higher than suburban region and form the UHI phenomenon. According to previous researches, UHI phenomenon can deteriorate ecological environment and influence human health(Kuang et al., 2018). The sustainable urban development need control and optimize the urban thermal environment for constructing a better living space.

Urban land surface temperature(LST), as one of the most important parameters for analyzing urban thermal environment, which is the radiative skin temperature of the urban surface(Bhati and Mohan, 2015; Kuang et al., 2018; Liu and Weng, 2008). Researchers usually utilized the LST to describe and analyze the urban thermal distribution especially the UHI phenomenon, and many researches indicated that LST is significant influenced by urbanization, land cover type and global climate, which all can change the LST(Madanian et al., 2018; Zhu et al., 2018). UTE, as a indispensable composition of urban ecosystem, closely related with human being, extreme UTE badly destroys urban ecosystem, such as UHI, which accelerate the urban LST increasing and deteriorate UTE, so it can be used to reflect and embody UTE. In order to improve UTE and mitigate UHI intensity, first and foremost, we should better understand the spatial distribution and variation's characteristics of the UTE, particularly the spatial and seasonal variation, which also can provide helpful information for other scientific research.

Traditionally, monitoring and measuring UTE usually depend on in-situ measurement or data collection from meteorological stations, which cost a lot and are usually difficult to gain(Zhu et al., 2018). In recent decades, thermal infrared remote sensing imagery, as a rapid, low cost and large-scale observation technology for global thermal environment, have made a great progress under vast research effort, and widely used in thermal environment research. The types of infrared sensors increased rapidly with a higher spatial resolution, shorter revisit time and larger observational range, which provide new chance for researchers to further study the thermal environment from regional scale to global scale. The thermal infrared data sources mainly including Landsat Thematic Mapper (TM)/Enhanced Thematic Mapper (ETM+)/Thermal Infrared Sensor (TRIS), Terra/Aqua Moderate Resolution Imaging Spectroradiometer

\footnotetext{
* Corresponding author
} 
(MODIS), ASTER and others, which are the most widely-used to study thermal environment. MODIS was commonly utilized in large regional or global study with a coarse spatial resolution, so MODIS is not appropriate to explore UTE. Landsat archive has a higher spatial resolution $(60 \mathrm{~m}-120 \mathrm{~m})$, high data quality and cost-effective to obtain(Zhou et al., 2018). In our study area and time periods, Landsat 8 TRIS data is available and cloudfree, therefore, we utilized Landsat 8 TRIS data in our study.

According to previous studies, UTE variation and distribution closely related to land use types, urban structure, urban surface feature materials even the air speed and cloud cover(Zullo et al., 2019). The influence factors of UTE have been extensively studied in recently years, especially the land covers, such as build-up area, water and vegetable, which were demonstrated closely related with UTE(Guo et al., 2019; Keeratikasikorn and Bonafoni, 2018; Madanian et al., 2018). However, the study of spatial distribution, heterogeneity and pattern of urban thermal environment was less researched than the former, which also is a significant research topic for sustainability development of urban environment. Chaiyapon et al. (Keeratikasikorn and Bonafoni, 2018) utilized main statistics to describe the urban thermal environment, such as mean, standard deviation, maximum and minimum LST value; Weng at al.(Weng et al., 2018) presented a innovative method by combining the Shannon's entropy and Pearson chi-square statistic to explore UTE in summer. Sun et al.(Sun et al., 2019) quantified the diurnal and seasonal of UTE using of 245 China cities to display the characteristics of UHI. Sabiha et al. (Sultana and Satyanarayana, 2018) combined land types and LST pattern to study the UTE in winter; Liu at al.(Liu and Weng, 2008) explored the seasonal variation of relationship between landscape pattern and LST; Peng et al. (Peng et al., 2018) compared the seasonal factors which result in the spatial distribution of LST. Victoria et al.(Miles and Esau, 2017) utilized MODIS LST production to explore the spatial and seasonal characteristics of UHI phenomenon. Qian et al.(Qian et al., 2018) utilized the maximum difference and standard deviation of temperature to explore the urban thermal heterogeneity through in-situ measurement. Most of previous studies usually ignored the UTE's seasonality, and paid more attention on summer, additionally, the spatial heterogeneity wasn't be well studied. There also have a lot of researches paid attention on the LST and it's effect factors, such as impervious surface area, vegetation area or water body, and want to explore the cooling effect of different surface features to decrease urban heat island or high LST distribution, which have made great progress(Firoozy Nejad and Zoratipour, 2019; He et al., 2019; Sherafati et al., 2018). In addition, most previous researches need to be combined with the actual situation of UTE, particularly gaining insight into it's detailed spatial information of different time periods, for mitigating the terrible problem on UTE. Therefore, more researches need to focus on the UTE itself, such as the heterogeneity of UTE, UHI characteristics on different seasons and sub-regions, which also have huge significance to optimize spatial thermal environment. On the other hand, the "heat island" region of urban area, which have the higher LST of all the urban region, have not been focused enough.

In this article, we selected a whole urban ecosystem, which take the urban nuclei as center covering complete urban scope, as our study area. Different seasons cloud-free Landsat 8 imagery were utilized to explore and describe the special-seasonal variation and distribution of UTE by analyzing UHI intensity, urban normalized LST, seasonal difference of UTE. The heterogeneity of UTE can be quantified by normalized LST, mean LST standard deviation(SD) and LST's amplitude variation. Meanwhile, we analyzed the spatial distribution of "heat island" region using landscape metrics index to detailed describe the UTE's variation and distribution pattern. In general, our study provided a better detailed understanding of UTE, particularly the spatial and seasonal variation under a whole urban system, to provide helpful information for decisionmakers for making efficient and accuracy policy on UTE management.

\section{MATERIALS AND METHODS}

\subsection{Study Area}

The city of Nanjing, Jiangsu province, China was selected as our main study area(longitude: $118^{\circ} 22-119^{\circ} 14 \mathrm{E}$; latitude: $31^{\circ} 14-32^{\circ} 37 \mathrm{~N}$ ), which situated in east of China, encompassing an area of $6587.02 \mathrm{~km}^{2}$ (see Figure 1). Nanjing is the capital city of Jiangsu, and regarded as the significant central city of the eastern coastal economic belt and the Yangtze River economic belt. The development of economy and population in Nanjing have increased rapidly during past decades, The population has increased almost 66\%, from 5.01 million in 1990 to 8.33 million in 2017. Nanjing's gross domestic product (GDP) has increased almost dozens of times, from approximately 16.09 billion in 1990 to more than $1,171.51$ billion in 2017. As for the climate, Nanjing has a subtropical monsoon climate which the annual average air temperature is about $15.4^{\circ} \mathrm{C}$, the annual average rainfall can reach $1157 \mathrm{~mm}$. In recent decades, The expansion of built-up area in Nanjing has increased sharply(from $515 \mathrm{~km}^{2}$ in 2000 to $1398 \mathrm{~km}^{2}$ in 2017) with rapid social and economic development, resulting in higher temperature in main urban area than suburbs. To comprehensive explore the UTE specialseasonal distribution and avoid the limitation of administrative boundaries, our study is of $5026.53 \mathrm{~km}^{2}$ circle area covering all of the central downtown and most of the suburb, whose central point is the Nanjing's central area Xinjiekou business district (longitude: $118^{\circ} 46^{\prime} 43^{\prime \prime E}$; latitude: $32^{\circ} 02^{\prime} 38^{\prime \prime N}$ ), and with the radius of $40 \mathrm{~km}$. The circular area was selected for two reasons, first, the most traditional study were limited by the administrative boundary, we want to research the total urban ecosystem and the whole thermal environment, which have more significance for guiding the urban planning. Second, the circular area is convenient for statistic and comparison in our study, so we divide our study into eight sub-regions for further analyzing(see in Figure1(b)).

\subsection{Data}

2.2.1 Landsat 8 TIRS images: Landsat 8 TIRS instrument has two thermal infrared bands at $100 \mathrm{~m}$ spatial resolution(Band 10 and Band11), which was considered as the one of the best thermal infrared sensors, can provide opportunity for monitoring the Land surface temperature, noted that the TRIS data have been resampled to $30 \mathrm{~m}$ by the USGS. Landsat 8 data can be download freely from the United States Geological Survey(USGS) website(https://earthexplorer.usgs.gov/). The TIRS data were used for retrieving LST. Four high-quality (cloud-free) scenes of Landsat 8 images(path/row 120/38) on 28 March, 2016, 21 July, 2017, 7 October 2017, 9, December, 2016 were chose for representing the four seasons of the year, the reason we chose from two years because there have no complete high-quality images of different seasons in the same year.

2.2.2 Other auxiliary data: The MODIS/Terra LST Daily L3 Global $1 \mathrm{~km}$ SIN Grid data (MOD11A1) and historical meteorological data was utilized to validate the LST result 
which retrieve from the Landsat 8 TRIS data(Darge et al., 2019). MOD11A1 LST data are retrieved by the split-window algorithm, which can be downloaded freely from https://wist.echo.nasa.gov/api/. The historical meteorological data was collected from the Urban weather station including the temperature data on a specified date, such as maximum temperature, minimum temperature, wind direction and so on.
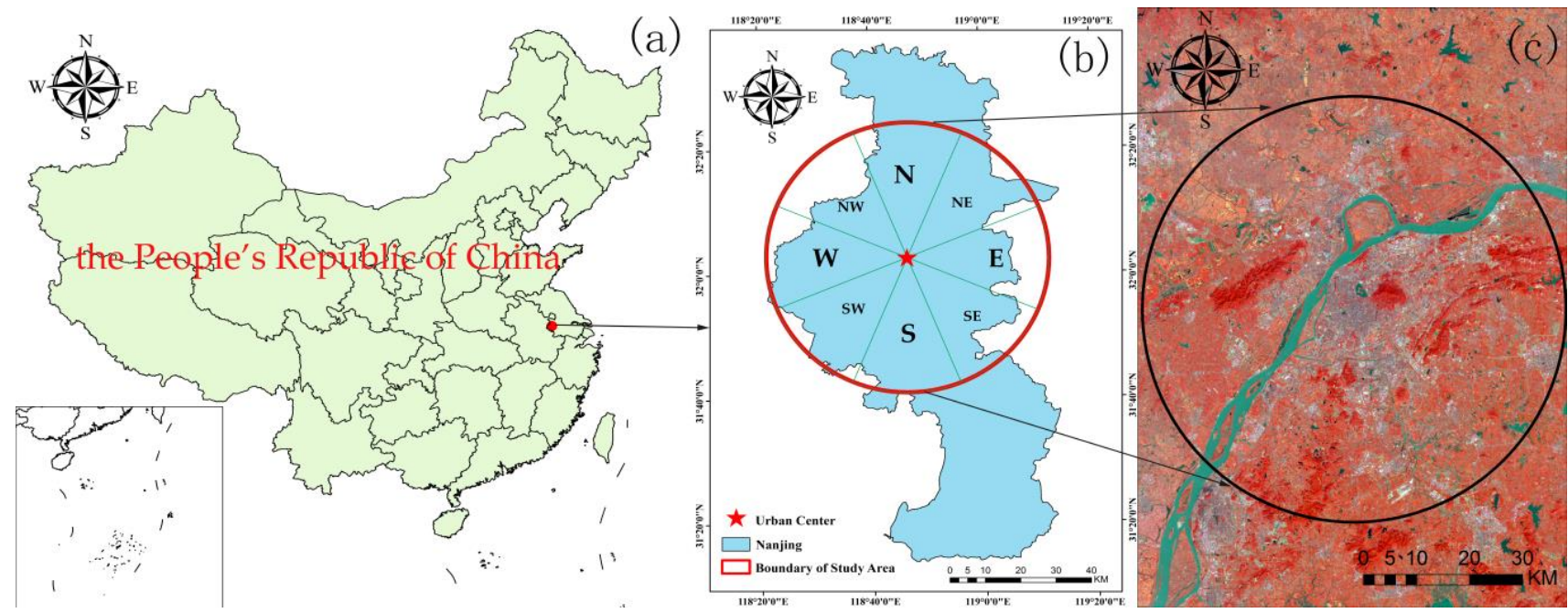

Figure 1. Map of study area of Nanjing, China.(a) Location of study area in China; (b) Division of study area; (c) Landsat 8 OLI false color composition image of study area(RGB=543)

\subsection{Data Pre-processing}

Before conducting temperature retrieval, Landsat TRIS data must be processed for reducing the errors due to instrumental variations in data acquisition, image noise, and misregistration, which will convert from the original digital number(DN) value to radiance $\left(\mathrm{W} /\left(\mathrm{m}^{2}\right.\right.$. sr. $\left.\left.\mu \mathrm{m}\right)\right)$ (Darge et al., 2019). Atmosphere correction of the Landsat 8 data, using FLAASH algorithm, was conducted on the ENVI 5.3 platform. After finishing the preprocess of Landsat 8 image data, all of the spatial data were converted to Lambert Azimuthal Equal Area Projection, with reference to the WGS84 datum. The study area boundary was used to clip the remote sensing data.

\subsection{LST Retrieval and Validation}

The LST of study area retrieved, using Landsat 8 Band10, based on the Radiative Transfer Equation (RTE) algorithm(GarcíaSantos et al., 2018; Voogt and Oke, 2003). The advantage of this algorithm is not only it needs less amount of parameters to retrieve LST comparing with other algorithm, such as monowindow algorithm and split-window algorithm, but also it was demonstrated that it has a high LST retrieve accuracy using Band 10 of Landsat 8 than split window algorithm and single channel method(Darge et al., 2019; Keeratikasikorn and Bonafoni, 2018; Shirani-bidabadi et al., 2019; Xiaolei Yu, 2014). In the status of data pre-processing, The landsat 8 thermal band 10 have been converted to at-sensor radiance at the top-of-atmosphere $\left(L_{\lambda}\right)$, next, Planck's radiance function was utilized to calculating brightness temperature. The LST can be expressed in equation as follows:

$$
T=\frac{K_{2}}{\ln \left(\frac{K_{1}}{L_{\lambda}}+1\right)}
$$

Where $T=$ At-sensor brightness temperature(in Kelvin),

$\mathrm{K}_{1}, \mathrm{~K}_{2}=774.89 \mathrm{~W} \mathrm{~m}^{-2} \mathrm{sr}^{-1} \mu^{-1}$ and $1321.08 \mathrm{~K}$, respectively(Guo et al., 2019).

$$
L_{\lambda}=\left[\varepsilon B\left(T_{S}\right)+(1-\varepsilon) L \downarrow\right]+L \uparrow
$$

Where $L_{\lambda}=$ Radiance recorded of channel 10

$\varepsilon=$ surface emissivity

$\tau=$ Atmospheric transmissivity at thermal infrared band

$B\left(T_{S}\right)=$ Radiation brightness of the blackbody

$L_{\downarrow}, L^{\uparrow}=$ Downwelling, upwelling atmospheric radiance

It's noted that $\varepsilon$ was calculated through the Normalized Difference Vegetation Index (NDVI) threshold method(Thanh Hoan et al., 2018; Xiaolei Yu, 2014), which is widely used in land surface emissivity calculating, respectively(Guo et al., 2019; Xiaolei $\mathrm{Yu}, 2014)$. Additionally, the $B\left(T_{S}\right)$ is computed based on the Plank's function, which can be expressed in the following Equation.3.

$$
B\left(T_{S}\right)=\frac{\left[L_{\lambda}-L \uparrow-\tau(1-\varepsilon) L \downarrow\right]}{\tau \varepsilon}
$$

After finishing the LST retrieval, we need to validate the result of the retrieval, as we know, it's hard to gain vast true ground surface measurement temperature, because of the unavailability and uncertainty with the concurrent time and position, so we learn from some researches, such as Yosef et al. (2019), Qin et al.(2011) and Srivastava et al.(2009). They all found that the LST retrieved from the Landsat 7 ETM+ and Landsat 8 TRIS have a difference about $2^{\circ} \mathrm{C}$ with the MODIS LST production(MOD11A1), based on this fact, we can validate our retrieved Landsat 8 LST result rapidly and accurately, and if the difference between the two less than $2^{\circ} \mathrm{C}$, the accuracy of LST retrieval is acceptable for further analysis(Darge et al., 2019). In addition, we also compared our retrieval results with the historical meteorological data, and calculated the correlation between them for further validation.

\subsection{LST Normalization and Calculation of UHI Intensity}

The standardization of LST can display the spatial distribution and pattern thermal environment in different time periods, because the LST comparison between different seasons is hard due to different climate background(Weng et al., 2018), the different absolute temperature in different season differ widely, 
but the distribution pattern of LST stay consistent, which will facilitate our analysis. On the other hands, the comparison of normalized LST in different seasons can represent the level of LST under the whole UTE. The standard LST can be calculated using the following Equation.4.

$$
L S T_{n}=\frac{L S T_{i}-L S T_{\min }}{L S T_{\max }-L S T_{\min }}
$$

Where $L S T_{n}$ is the normalized LST, $L S T_{i}$ represents the individual LST of pixel $i, L S T_{\min }$ and $L S T_{\max }$ is the minimum and maximum temperature of our study area.

After normalizing the LST of each time periods, we need to classify the standard LST data to conduct further study. According the mean temperature and standard deviation of every standard LST results, we divided each results into five levels: very low temperature zone $\left(T \leq T_{\text {mean }}-1.5 *\right.$ std $)$, low temperature area( $\left.T_{\text {mean }}-1.5 * s t d<T<T_{\text {mean }}-s t d\right)$, medium temperature area $\left(T_{\text {mean }}-s t d<T \leq T_{\text {mean }}+\right.$ std $)$, high temperature area $\left(T_{\text {mean }}+s t d<T \leq T_{\text {mean }}+1.5 * s t d\right)$, very high temperature area $\left(T>T_{\text {mean }}+1.5 * s t d\right)$.

Based on the classification of temperature of study area, we can describe the UTE further, as we know, UHI is a common phenomenon in many metropolis including Nanjing, which dramatically change the UTE. Description of UHI intensity can embody and reflect the UTE more quantitatively and comparably during different time periods and regions. So the urban heat island ratio index, suggested by Xiong et al.(2012), to quantify the UHI intensity, which was shown in the Equation.5.

$$
\text { SUHI intensity }=\frac{1}{100} \sum_{i=1}^{n} W_{i} P_{i}
$$

Where $n$ is the number of temperature level which more than the medium temperature level; $W_{i}$ represents the weight of temperature level $i$, and $P_{i}$ is the percentage of temperature level $i$.

\subsection{Spatial-seasonal Analysis of UTE}

2.6.1 The heterogeneity and variation analysis of UTE: For exploring the spatial variation and heterogeneity of LST in different zones and time periods, we not only analyzed the whole region, but also divided our study area into eight subareas based on the shape feature of our study area, which can represent different situation at directions. The heterogeneity of the UTE was quantified by standard deviation(SD) and the different between the upper and lower quartiles(DULQ), the reason we used the DULQ because there have some abnormal LST value(extreme high LST, such as the steel mill, power station or other heavy industry factories ), so the upper and lower quartiles are more objective to quantify the global heterogeneity of LST. The mean temperature and the standard deviation of each zones were also counted for analyzing the detailed variation and the zone's differences. The UHI intensity of each seasons and each sub-regions were researched based on different directions. The destination of all the steps above is to explore the spatial distribution and distribution heterogeneity of UTE.

2.6.2 Spatial-distribution pattern of urban thermal region: In the UTE, the spatial distribution pattern of which need to be further explored, particularly the extreme high temperature region( $\quad T>T_{\text {mean }}+s t d$, cotaining level 4 and level $5 \quad$ ), which is the " heat island " in our urban thermal environment, and these areas have the most serious impact on the living environment of human being, plants and animals than any other regions. Exploring the special distribution and variation of urban extreme heated regions can provide meaningful information for UTE management. The structure of heat region under different seasons were analyzed utilizing landscape metrics including patch density (PD), Patch number(PN), Aggregation index(AI), Mean patch size(MPS), Total area(TA) and Patch cohesion index(PCI) (Table 1). All of the landscape metrics were computed in Fragstats 4.2 software, and conducting analysis based on these metrics during different

\begin{tabular}{|c|c|c|c|}
\hline Landscape Metrics & Description & Unit & Range \\
\hline Patch density (PD) & $\begin{array}{l}\text { The number of patch per square } \\
\text { kilometer }\end{array}$ & count $/ \mathrm{km}^{2}$ & $>0$ \\
\hline Patch number(PN) & $\begin{array}{l}\text { The total number of patches in } \\
\text { the landscape }\end{array}$ & count & $>0$ \\
\hline $\begin{array}{l}\text { Aggregation } \\
\text { index(AI) }\end{array}$ & $\begin{array}{l}\text { Mean distance to the nearest } \\
\text { same patch }\end{array}$ & None & $0-100$ \\
\hline $\begin{array}{l}\text { Mean patch } \\
\text { size(MPS) }\end{array}$ & Mean size of the total patch & $\mathrm{km}^{2}$ & $>0$ \\
\hline Total area(TA) & $\begin{array}{l}\text { The total area of patch in the } \\
\text { landscape }\end{array}$ & $\mathrm{km}^{2}$ & $>0$ \\
\hline $\begin{array}{l}\text { Patch cohesion } \\
\text { index }(\mathrm{PCI})\end{array}$ & $\begin{array}{l}\text { The physical connectedness of } \\
\text { surrounding patch }\end{array}$ & None & $0-100$ \\
\hline
\end{tabular}
seasons.

Table 1. Descriptions of selected landscape indexes

\section{RESULTS AND DISCUSSION}

\subsection{Land Surface Temperature Retrieval and Validation}

The LST of our study area was derived from Landsat 8 TRIS data by employing RTE method in different seasons were shown in the Figure 2, we can find that the relatively higher temperature usually concentrated in the urban area, and the suburban area shows a lower temperature than the urban region, which was called the urban heat island phenomenon. The spatial distribution of UTE showed quite different distribution pattern between four seasons.

In order to validate the LST retrieval results, we compared them with the MODIS LST production(MOD11A1) and historical temperature data of Nanjing. We found that the difference of the average LST of our study area, retrieved from the Landsat 8 TRIS data, and the average LST from MOD11A1 production are within $2^{\circ} \mathrm{C}$. In addition, the $\mathrm{R}^{2}$ (correlation between observed value and predicted value) of average retrieval LST result from the TRIS data and historical temperature is 0.9693 , which represents a acceptable retrieval accuracy. Based on verification above, the LST retrieval map satisfied the needs of our further study.

\subsection{Spatial-seasonal Heterogeneity Analysis and UHI Intensity Calculation}

After retrieving the LST of different seasons, we calculated the standard deviation(SD) and difference between upper and lower quartiles(DULQ) under different seasons, which is shown in the 
Figure 3. In summer, all of the two indexes is the largest, which meant summer has the largest heterogeneity, and winter has the lowest. The spring and autumn have the similar heterogeneity, which need further study. Overall, the heterogeneity varied obviously with the seasons.
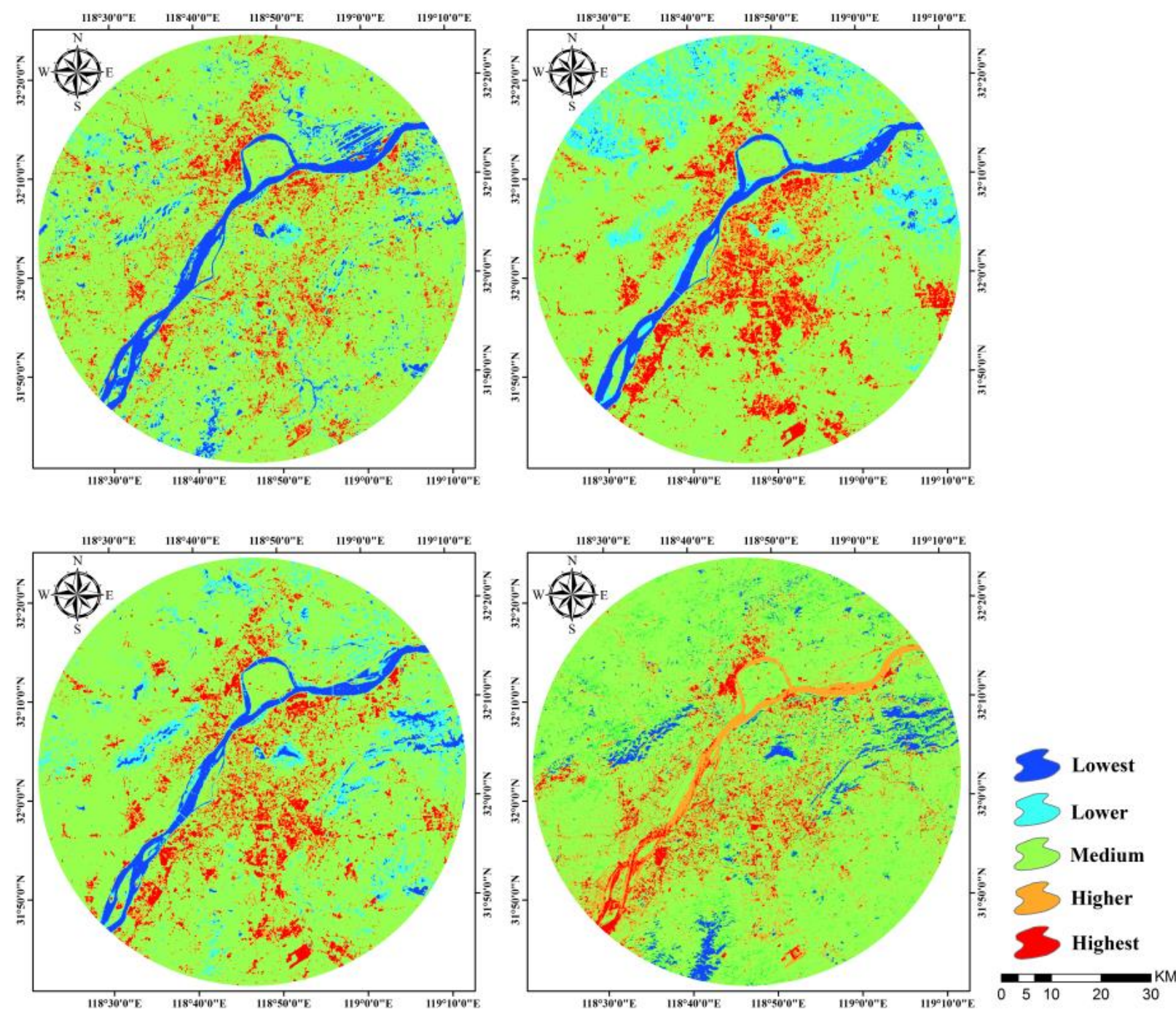

Figure 2. Land surface temperature of different seasons

In order to further detailed analyze the heterogeneity of our study, we decomposed the study area, compared the average LST of different directions and the SD under different regions, as shown in the Figure 4, according to previous findings, UHI intensity is closed to land cover, in our study, there have large difference of land cover composition and urban zoning between different directions, which caused different LST distribution. The standard deviation of LST can represent the zonal LST's change level, which is a essential element to describe the UTE. Additionally, the standard deviation of LST during different seasons shows a different trend, especially in summer, the SD of LST is extremely higher than any other seasons of directions. As for the different directions, the NE and SW directions have the higher SD of LST during all seasons, the SE and W directions have the lower LST's SD, especially in summer, autumn and winter. The overall level of SD value was linking to the seasonal change, but the difference in directions may caused by the regional differences, such as the number of land cover type, the composition of land cover or human activity. As for the mean LST, the directions of SE, S, SW have the high mean LST, which also have high UHI intensity.

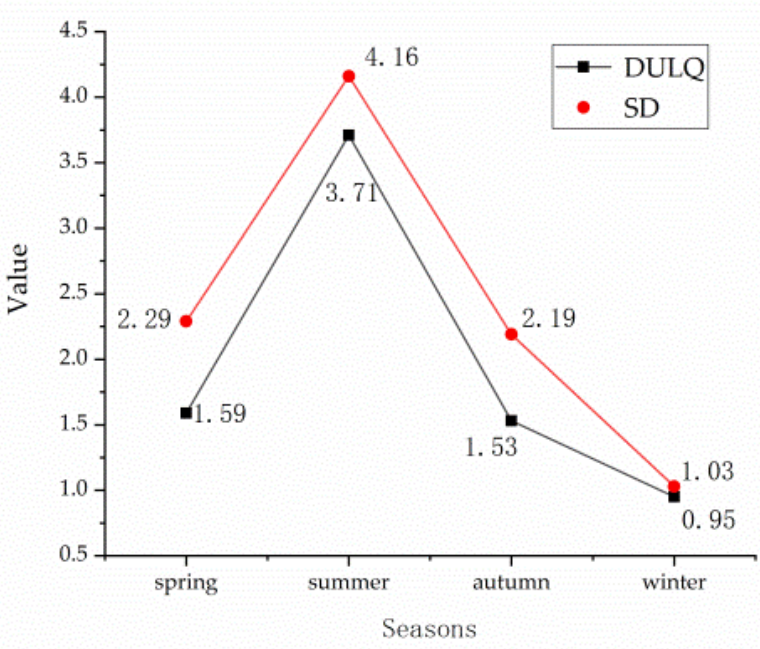

Figure 3. Seasonal LST's standard deviation(SD) and difference between upper and lower quartiles(DULQ) 


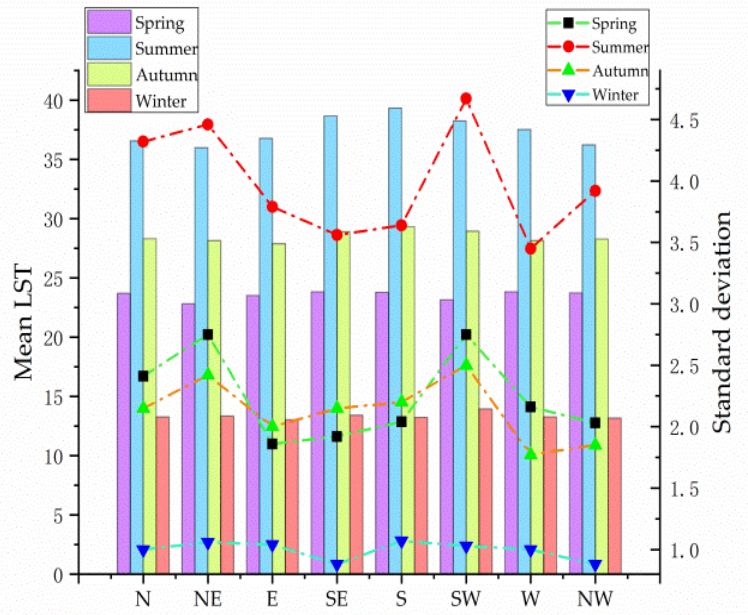

Directions

Figure 4. Distribution of mean LST and the variation of LST's standard deviation

Base on the retrieval LST results, we reclassified these LST map into four temperature levels, and calculated the urban heat island index, as shown in the Table 2, from which we can conclude that the intensity of urban heat island in summer is the highest, and in other seasons, this phenomenon has slowed down.
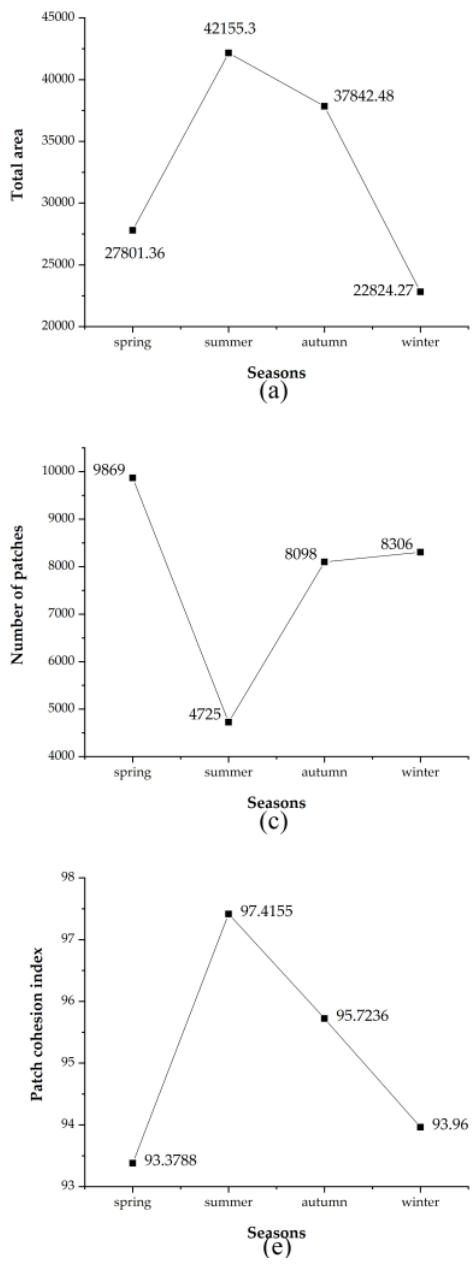

Figure 5. Landscape metrics of urban heat regions,

\begin{tabular}{ccccc}
\hline Season & Spring & Summer & Autumn & Winter \\
\hline UHI intensity & 0.1225 & 0.1578 & 0.1289 & 0.1144 \\
\hline
\end{tabular}

Table 2. Urban heat island index under different seasons

\subsection{Spatial distribution and pattern of urban heated region}

Urban heated region, which refer to the high temperature area $\left(T>T_{\text {mean }}+1.5 *\right.$ std $)$ and represent the "heat island" of urban heat island phenomenon in UTE, play a crucial role in the UTE. In our study, we used six landscape metrics to describe the spatial distribution and pattern of urban heated region, the following Figure 5 shows the five landscape metrics of urban heat region of different seasons, we can find that summer has the largest heated region area, however, the number of which is the least than other seasons. Additionally, winter's TA is the least and MPS is smallest of all the seasons, which contain many fragmentized heated regions in the study area, in other words, the area of heated regions in winter become less and which distribute more dispersedly than other seasons. The PCI and $\mathrm{AI}$ indicate that the heated regions of our study area tend to be concentrated and highly connected in summer, and weakening in other seasons especially in winter. The spatial clustering and increase of urban heat regions result in the variation of UTE, which will aggregate the UHI intensity especially in summer, so this spatial distribution of heated regions need be focused on based on spatial-seasonal characteristics.
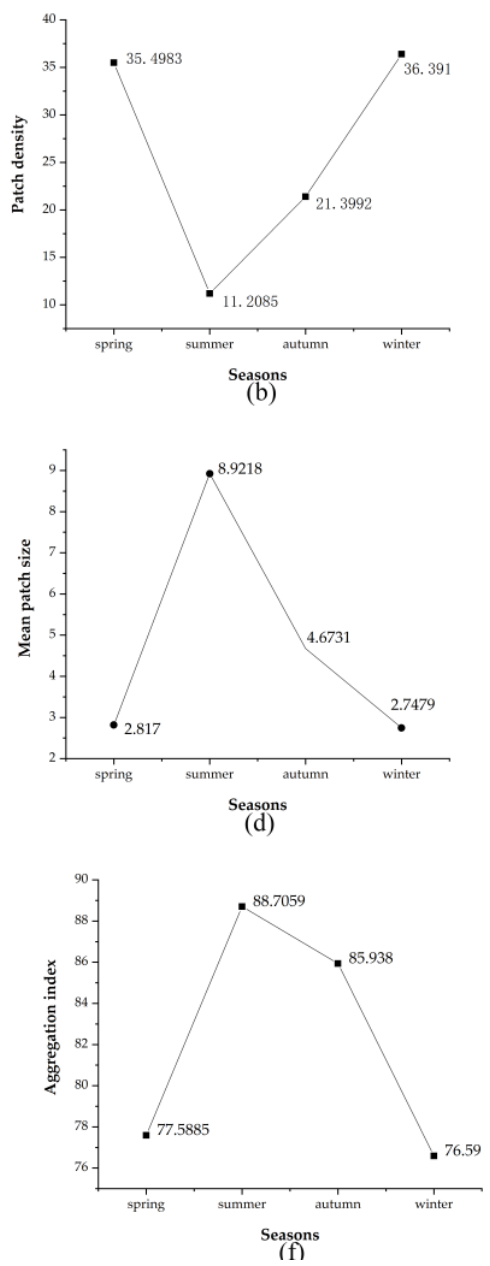

(a) TA; (b) PD; (c) NP; (d) MPS; (e) PCI; (d) AI 


\section{CONCLUSION}

In this paper, we utilized the Landsat 8 TRIS imagery to explore the spatial-seasonal variation, heterogeneity and distribution of UTE by analyzing UHI intensity, comparing seasonal normalized LST, and further described the spatial distribution and pattern of urban heated region through landscape metrics index. The relevant conclusions of our study are as follows:

(1) The UHI intensity of Nanjing reaches the peak in summer, which meant the city has a worst thermal environment for human being, plants and animals, and with a high spatial heterogeneity, additionally, different districts have various thermal environment. So policymakers need to pay close attention to the summer, and different strategies need to be implemented due to the difference between each regions or directions. The heterogeneity of UTE provide a meaningful information for urban environment management, where the decreasing of heterogeneity can become a future direction of research.

(2) Our results also revealed that urban heated region's spatial distribution pattern have a seasonal variations. The structure of UTE changes with seasons, the clustering effect is obvious in high-LST seasons, and decreased in low-LST seasons, which meant that high LST usually together with high spatial aggregation of heated regions. This phenomenon was interesting and need pad more attention on to explore the factors. So based on our results, the distribution of urban "heat island" is another perspective to understand the UTE, which should be referenced to design urban development planning. we think there have a significant idea and method to mitigate bad UTE, which is breaking the spatial aggregation and cut off the decreasing the spatial connectivity, and try to decrease the area of heated region by utilizing some cooling methods. Overall, the heated region in our city, which can do harm to our living environment, should be controlled and decreased by urban administrators, the distribution regularity we found need to be referenced.

(3) The results of our study expanded our understanding of the variation of UTE among different seasons, which can be referenced to formulate specific measures to solve the UHI phenomenon. Summer needs to be focused first, and in other seasons, the UTE also need to optimize further. The regional urban planning, which was made differ from each area, need pay more effort. The detailed urban zonal planning based on the current situation of thermal environment should be enacted in the future.

\section{ACKNOWLEDGEMENTS}

This study was supported by the Priority Academic Program Development of the Jiangsu Higher Education Institutions..

\section{REFERENCES}

Bhati, S., Mohan, M., 2015. WRF model evaluation for the urban heat island assessment under varying land use/land cover and reference site conditions. Theoretical and Applied Climatology, 126(1-2), 385-400.

Chakraborty, T., Lee, X., 2019. A simplified urban-extent algorithm to characterize surface urban heat islands on a global scale and examine vegetation control on their spatiotemporal variability. International Journal of Applied Earth Observation and Geoinformation, 74, 269-280.

Darge, Y.M., Hailu, B.T., Muluneh, A.A., Kidane, T., 2019. Detection of geothermal anomalies using Landsat 8 TIRS data in Tulu Moye geothermal prospect, Main Ethiopian Rift. International Journal of Applied Earth Observation and Geoinformation, 74, 16-26.

Deilami, K., Kamruzzaman, M., Liu, Y., 2018. Urban heat island effect: A systematic review of spatio-temporal factors, data, methods, and mitigation measures. International Journal of Applied Earth Observation and Geoinformation, 67, 30-42.

Firoozy Nejad, M., Zoratipour, A., 2019. Assessment of LST and NDMI indices using MODIS and Landsat images in Karun riparian forest. Journal of Forest Science, 65(No. 1), 27-32.

García-Santos, V., Cuxart, J., Martínez-Villagrasa, D., Jiménez, M., Simó, G., 2018. Comparison of Three Methods for Estimating Land Surface Temperature from Landsat 8-TIRS Sensor Data. Remote Sensing, 10(9), 1450.

Guo, L., Liu, R., Men, C., Wang, Q., Miao, Y., Zhang, Y., 2019. Quantifying and simulating landscape composition and pattern impacts on land surface temperature: A decadal study of the rapidly urbanizing city of Beijing, China. Sci Total Environ, $654,430-440$.

He, B.-J., Zhao, Z.-Q., Shen, L.-D., Wang, H.-B., Li, L.-G., 2019. An approach to examining performances of cool/hot sources in mitigating/enhancing land surface temperature under different temperature backgrounds based on landsat 8 image. Sustainable Cities and Society, 44, 416-427.

Keeratikasikorn, C., Bonafoni, S., 2018. Urban Heat Island Analysis over the Land Use Zoning Plan of Bangkok by Means of Landsat 8 Imagery. Remote Sensing, 10(3), 440.

Kuang, W., Liu, A., Dou, Y., Li, G., Lu, D., 2018. Examining the impacts of urbanization on surface radiation using Landsat imagery. GIScience \& Remote Sensing, 56(3), 462-484.

Liu, H., Weng, Q., 2008. Seasonal variations in the relationship between landscape pattern and land surface temperature in Indianapolis, USA. Environ Monit Assess, 144(1-3), 199-219.

Madanian, M., Soffianian, A.R., Koupai, S.S., Pourmanafi, S., Momeni, M., 2018. Analyzing the effects of urban expansion on land surface temperature patterns by landscape metrics: a case study of Isfahan city, Iran. Environ Monit Assess, 190(4), 189.

Miles, V., Esau, I., 2017. Seasonal and Spatial Characteristics of Urban Heat Islands (UHIs) in Northern West Siberian Cities. Remote Sensing, 9(10), 989.

Peng, J., Jia, J., Liu, Y., Li, H., Wu, J., 2018. Seasonal contrast of the dominant factors for spatial distribution of land surface temperature in urban areas. Remote Sensing of Environment, $215,255-267$.

Qian, Y., Zhou, W., Hu, X., Fu, F., 2018. The Heterogeneity of Air Temperature in Urban Residential Neighborhoods and Its Relationship with the Surrounding Greenspace. Remote Sensing, 10(6), 965. 
Qin, Q., Zhang, N., Nan, P., Chai, L., 2011. Geothermal area detection using Landsat ETM+ thermal infrared data and its mechanistic analysis-A case study in Tengchong, China. International Journal of Applied Earth Observation and Geoinformation, 13(4), 552-559.

Sherafati, S., Saradjian, M.R., Rabbani, A., 2018. Assessment of Surface Urban Heat Island in Three Cities Surrounded by Different Types of Land-Cover Using Satellite Images. Journal of the Indian Society of Remote Sensing, 46(7), 1013-1022.

Shirani-bidabadi, N., Nasrabadi, T., Faryadi, S., Larijani, A., Shadman Roodposhti, M., 2019. Evaluating the spatial distribution and the intensity of urban heat island using remote sensing, case study of Isfahan city in Iran. Sustainable Cities and Society, 45, 686-692.

Srivastava, P.K., Majumdar, T.J., Bhattacharya, A.K., 2009. Surface temperature estimation in Singhbhum Shear Zone of India using Landsat-7 ETM+ thermal infrared data. Advances in Space Research, 43(10), 1563-1574.

Sultana, S., Satyanarayana, A.N.V., 2018. Urban heat island intensity during winter over metropolitan cities of India using remote-sensing techniques: impact of urbanization. International Journal of Remote Sensing, 39(20), 6692-6730.

Sun, R., Lü, Y., Yang, X., Chen, L., 2019. Understanding the variability of urban heat islands from local background climate and urbanization. Journal of Cleaner Production, 208, 743-752.

Thanh Hoan, N., Liou, Y.-A., Nguyen, K.-A., Sharma, R., Tran, D.-P., Liou, C.-L., Cham, D., 2018. Assessing the Effects of Land-Use Types in Surface Urban Heat Islands for Developing Comfortable Living in Hanoi City. Remote Sensing, 10(12), 1965.

United Nations, 2018. World Urbanization Prospects: The 2018 Revision.

Voogt, J.A., Oke, T.R., 2003. Thermal remote sensing of urban climates. Remote Sensing of Environment, 86(3), 370-384.

Weng, Q., Firozjaei, M.K., Sedighi, A., Kiavarz, M., Alavipanah, S.K., 2018. Statistical analysis of surface urban heat island intensity variations: A case study of Babol city, Iran. GIScience \& Remote Sensing, 56(4), 576-604.

Xiaolei Yu, X.G.a.Z.W., 2014. Land Surface Temperature Retrieval from Landsat 8 TIRS-Comparison between Radiative Transfer Equation-Based Method, Split Window Algorithm and Single Channel Method. Remote Sensing, 6, 9829-9852;

Xiong, Y., Huang, S., Chen, F., Ye, H., Wang, C., Zhu, C., 2012. The Impacts of Rapid Urbanization on the Thermal Environment: A Remote Sensing Study of Guangzhou, South China. Remote Sensing, 4(7), 2033-2056.

Yu, Z., Yao, Y., Yang, G., Wang, X., Vejre, H., 2019 Spatiotemporal patterns and characteristics of remotely sensed region heat islands during the rapid urbanization (1995-2015) of Southern China. Sci Total Environ, 674, 242-254.

Zhou, D., Xiao, J., Bonafoni, S., Berger, C., Deilami, K., Zhou, Y., Frolking, S., Yao, R., Qiao, Z., Sobrino, J., 2018. Satellite Remote Sensing of Surface Urban Heat Islands: Progress, Challenges, and Perspectives. Remote Sensing, 11(1), 48.
Zhou, D., Zhao, S., Liu, S., Zhang, L., Zhu, C., 2014. Surface urban heat island in China's 32 major cities: Spatial patterns and drivers. Remote Sensing of Environment, 152, 51-61.

Zhu, X., Wang, X., Yan, D., Liu, Z., Zhou, Y., 2018. Analysis of remotely-sensed ecological indexes' influence on urban thermal environment dynamic using an integrated ecological index: a case study of Xi'an, China. International Journal of Remote Sensing, 40(9), 3421-3447.

Zullo, F., Fazio, G., Romano, B., Marucci, A., Fiorini, L., 2019. Effects of urban growth spatial pattern (UGSP) on the land surface temperature (LST): A study in the Po Valley (Italy). Sci Total Environ, 650(Pt 2), 1740-1751. 